Olivar, junio 2018, vol. 18, $\mathrm{n}^{\circ}$ 27, e029. ISSN 1852-4478

Universidad Nacional de La Plata

Facultad de Humanidades y Ciencias de la Educación

Centro de Estudios de Teoría y Crítica Literaria

\title{
Fernando Aramburu, Patria, Buenos Aires, Tusquets, 2016, 648 pp.
}

Miglierina, Luciano Instituto de Investigaciones en Humanidades y Ciencias

Sociales (IdIHCS) - Universidad Nacional de La Plata -CONICET, Argentina

Cita sugerida: Miglierina, L.(2018). [Revisión del libro Fernando Aramburu, Patria por F. del Aramburu] Olivar, 18 (27), e029. https://doi.org/10.24215/18524478e029 
Fernando Aramburu, Patria, Buenos Aires, Tusquets, 2016, 648 pp.

Luciano Miglierina

Instituto de Investigaciones en Humanidades y Ciencias

Sociales (IdIHCS) - Universidad Nacional de La Plata -

CONICET, Argentina

Fernando Aramburu nació en San Sebastián en 1959. En 1982 se licenció en filología española en la Universidad de Zaragoza. Durante su juventud en San Sebastián fue uno de los fundadores del Grupo CLOC de Arte y Desastre, de corte surrealista y contracultural. Desde 1985 reside en Alemania, donde impartió clases hasta 2009, cuando decidió abandonar la docencia para dedicarse exclusivamente a la creación literaria.

En 1996 se da a conocer con Fuegos con limón, novela basada en las experiencias juveniles vividas con CLOC. En 2000 aparece el primer libro de la Trilogía de Antíbula, Los ojos vacíos (seguido de Bami sin sombra y La gran Marivián) con el cual fue galardonado con el Premio Euskadi de literatura en castellano. Sin embargo, será Años lentos (2012), ganadora del Premio Tusquets de Novela, la que lo coloca dentro del panorama narrativo como una de las nuevas voces de las letras hispánicas. Y es, sin dudas, Patria, publicada en 2016, el título que consagra de manera definitiva al autor vasco.

Galardonada con premios distinguidos como el Premio Nacional de Narrativa, el Francisco Umbral, el Premio de la Crítica, el Dulce Chacón y merecedora de la II Beca del Fondo Antonio López Lamadrid de Apoyo a la Creación Literaria, Patria de Fernando Aramburu se instala como una de las grandes novelas de los últimos tiempos.

En la novela, Aramburu vuelve a centrarse, al igual que hizo diez años antes en el libro de relatos Peces de la amargura (2006, Premio Dulce Chacón, Premio Real Academia Española), en las víctimas del terrorismo de ETA, entregando una novela que muestra la otra cara del conflicto, punto de vista escaso dentro de la narrativa vasca.

Divididas las más de seiscientas páginas en ciento veinticinco capítulos breves, Patria recorre la vida de los personajes afectados, de una manera u otra, por la lucha de ETA. Gracias al recurso de la analepsis podemos conocer la historia de cada uno de ellos, y cómo sus vidas derivan en la situación actual en que el lector los encuentra. La narración de Patria se ve constantemente interrumpida por el pensamiento de los personajes por medio del discurso indirecto libre.

Las dos familias protagonistas pueden ser tomadas como analogía de la sociedad (recurso al que apelan numerosas novelas: la familia como estereotipo de la sociedad), representantes de tensiones, acercamientos, acuerdos y conflictos entre ellas y sus miembros, e incluso entre los propios de una misma familia.

La novela se abre con la decisión de Bittori de regresar a vivir a la casa del pueblo de donde debió irse por precaución luego de la muerte de su marido, Txato, a manos de un etarra. Frente a la tumba de su marido Miren, impulsada por el hecho de que ETA había anunciado el abandono de las armas, le cuenta su proyecto de volver del exilio al que se vio sometida. Bittori siente la misma emoción que experimenta Sancho al final del Quijote al observar un puñado de casas y de tierra a las que considera su patria. La patria es, para Sancho y para Bittori, ese lugar al que uno se siente ligado. A pesar de los hechos trágicos que le tocó vivir allí, el pueblo sigue siendo para la mujer del Txato su lugar, su patria. La novela plantea un juego semántico con la palabra "patria". Actualmente "patria" suele designar a lo que sería la tierra natal o adoptiva a la que un individuo se siente ligado afectivamente por vínculos de diversa índole, como afectivos, culturales, históricos, etc., independientemente de que haya o no nacido en ella. La palabra proviene del latín "patrŭa" (familia o 
clan), y "patris" (tierra paterna). Asimismo "patris" también hace referencia al "pater" (padre), es decir a la cabeza de una familia o un clan y, por extensión, de un pueblo. La novela juega con todos estos sentidos, porque la "patria" es el pueblo, pero también lo es la familia y el padre, el cabeza de familia. Bittori se ve impedida de la patria en todos los sentidos: se exilia del pueblo y el Txato es asesinado. Dentro de la novela la figura del padre como jefe del clan se ve cercenada o diluida. Los otros hombres de las familias no se alzan como cabezas de familia, Xabier, el hijo de Bittori y Txato es soltero; Joxian, marido de Miren y por lo tanto el "pater" de la otra familia protagonista, "era de renegar en voz baja y de largarse al bar en cuanto olfateaba discordia" y todo se lo dejaba a Miren: "la educación de los hijos, las enfermedades, la paz de la casa" (44); Gorka, el hijo menor de Joxian, es homosexual y vive solo junto a su pareja; y Joxe Mari, el hijo mayor; está encarcelado. Frente a esta ausencia de una figura paterna fuerte dentro de la novela, las mujeres (Bittori, Miren, Arantxa, Nerea) se alzan como personajes dominantes.

El regreso de Bittori al pueblo es el que pone en funcionamiento la narración. Su regreso desenmascara la aparente tranquilidad en la que cree vivir el pueblo. El cura Serapio le pide que no se deje ver por el lugar para no entorpecer el proceso de paz "pues ha llegado el momento de que nos perdonemos unos a otros" (121). La idea de reconciliación y de perdón es una presencia fantasmagórica que perturba a muchos de los personajes a lo largo de la novela. La familia del Txato está necesitada del pedido de perdón. Al respecto Miren le dice a su hermano Xabier:

Estáis emocionalmente bloqueados. Estáis la ama y tú en un agujero de pena y de rencor y de melancolía del que no podéis salir y no sé yo si queréis salir. Yo he tocado fondo. Ya basta. Algo dentro de mí tiene que cambiar. Por eso, después de asesorarme, había pensado en ir a donde uno de esos asesinos y decirle: esto me hicisteis, estas son las consecuencias, quédatelas, te las regalo, y después marcharme lejos con su perdón o sin él. (135. Destacado nuestro)

Del otro lado, Joxe Mari también comienza a sentir remordimientos por lo que ha hecho como miembro de ETA. Las visitas de sus hermanos, Gorka y Arantxa, terminan por quebrarlo y enfrentarlo con sus propios fantasmas: la idea de que lo vean como un terrorista arrepentido y, por lo mismo, un traidor a la causa. Joxe Mari necesita liberarse de la culpa por las muertes causadas (aunque si es el asesino del Txato o no queda sumido en la ambigüedad) y le escribe, finalmente, a Bittori una carta en la que dice: "os pido perdón a ti y a tus hijos. Lo siento mucho. Si pudiera dar marcha atrás lo haría. No puedo. Lo siento. Ojalá me perdones” (632).

Por último, Miren y Bittori dejan atrás la enemistad cuando "el encuentro se produjo a la altura del quiosco de música. Fue un abrazo breve. Las dos se miraron un instante a los ojos antes de separarse. ¿Se dijeron algo? Nada. No se dijeron nada" (642). No se dicen nada pues no hace falta, las culpas ya están perdonadas y las disculpas dichas.

El gran acierto de Fernando Aramburu es el no haber planteado la historia entre dos bandos antagónicos, entre buenos y malos. No obstante, sí identifica claramente como víctimas a aquéllos que fueron asesinados y maltratados por no comulgar con las ideas de ETA. Los etarras, representados por Joxe Mari, son vistos como jóvenes que se dejaron engañar por la propaganda terrorista (un amigo de Joxe Mari le señala a Gorka al respeto de un artículo sobre ETA: "muy bueno tu artículo de ayer. No entendí nada pero me gustó, sigue así”) y que terminaron cometiendo atrocidades de las que se arrepienten. Aramburu no demoniza a los terroristas, no escapa de su humanidad (en la presentación del libro en Pinamar señalaba al respecto que antes que asesinos los etarras siguen siendo seres humanos) y los representa como hombres que se han equivocado. La humanización viene dada con el pedido de perdón sobre lo que se ha hecho u omitido, y la paz que tanto necesita Bittori para irse en ella.

Gorka representa a aquellos muchachos que se salvaron de la influencia de la propaganda gracias a la cultura, a la lectura. Para él la lucha vasca se puede hacer por otros medios y en otros espacios, a través de la escritura y la actividad cultural: "hago programas de radio en euskera, escribo libros en euskera, ayudo a nuestra cultura. Es mi manera de aportar algo a nuestro pueblo, pero algo constructivo, sin dejar a mi paso un montón de huérfanos y viudas"(582. Destacado nuestro). Siguiendo a José Carlos Mainer y lo expuesto en su artículo "Patria voraz" (El Pais-Babelia, 29 de agosto de 2016), ésta es la función que cumple, o debe cumplir 
la literatura vasca, y dentro de la novela Aramburu la presenta por medio de un escritor (alter ego de él mismo) que sostiene al respecto que

Este proyecto de componer, por medio de la ficción literaria, un testimonio de las atrocidades cometidas por la banda terrorista surge en mi caso por una doble motivación. Por un lado, la empatía que les profeso a las víctimas del terrorismo. Por el otro, el rechazo sin paliativos que me suscitan la violencia y cualesquiera agresiones dirigidas contra el Estado de Derecho. (551)

Patria es una novela que trata las culpas y la reconciliación. Trata a las víctimas como víctimas y a los victimarios como victimarios pero aquí no hay ángeles ni demonios sino humanos que han errado, asesinos que no dejan de ser humanos y por eso tienen la capacidad de pedir perdón. Hay víctimas nubladas por el rencor pero que se humanizan y pueden perdonar. Patria es una novela que plantea el conflicto de ETA en toda su complejidad. Por todo ello los personajes no tienen apellido, porque la novela no se trata de una víctima y un asesino particulares se trata de mostrar que cualquiera (algún Txato, algún Joxe Mari, alguna Bittori, alguna Miren) podía verse envuelto y terminar siendo una víctima o un culpable, pero en ambos casos con el sufrimiento a cuestas. 